九州大学学術情報リポジトリ

Kyushu University Institutional Repository

\title{
Seed Germination Response to Temperature and Salinity Stress in Lilim longiflorum and L. formosanum
}

Hiramatsu, Michikazu

Laboratory of Horticultural Science, Division of Agricultural Botany, Department of Plant Resoruces, Faculty of AGriculture, Kyushu University

Yoshimura, Kiyomi

Laboratory of Horticultural Science, Agricultural PRoduction, Engineerig and Economics Course, School of Agriculture, Kyushu University

Okubo, Hiroshi

Laboratory of Horticultural Science, Division of Agricultural Botany, Department of Plant Resoruces, Faculty of AGriculture, Kyushu University

Huang, Chi We i

Department of Horiculture, Naional Chiayi University

他

https://doi.org/10.5109/4590

出版情報: 九州大学大学院農学研究院紀要. 49 (2)，pp.301-305，2004-10-01. Faculty of Agriculture, Kyushu University

バージョン :

権利関係 : 
J. Fac. Agr., Kyushu Univ., 49 (2), 301-305 (2004)

\title{
Seed Germination Response to Temperature and Salinity Stress in Lilium longiflorum and $L$. formosanum
}

\author{
Michikazu HIRAMATSU*, Kiyomi YOSHIMURA ${ }^{1}$, Hiroshi OKUBO, \\ Chi Wei HUANG ${ }^{2}$ and Kuang Liang HUANG ${ }^{2}$
}

\author{
Laboratory of Horticultural Science, Division of Agricultural Botany, \\ Department of Plant Resources, Faculty of Agriculture, \\ Kyushu University, Fukuoka 812-8581, Japan \\ (Received June 30, 2004 and accepted July 13, 2004)
}

\begin{abstract}
Seed germination response to different degree of thermal and salinity treatments for two closely related, but ecologically distinct bulbous species, Lilium longiflorum and L. formosanum was investigated, in order to clarify optimum temperature for seed germination and whether the tolerance to salinity stress is different between the species. Among seven constant thermal treatments for seeds collected from two natural populations of $L$. longiflorum and one of $L$. formosanum, treatments of 25 and $30^{\circ} \mathrm{C}$ significantly reduced the final germination percentage approximately less than 80 and $10 \%$, respectively, of the treatments below $20^{\circ} \mathrm{C}$. Treatment exposed to 17.5 or $20^{\circ} \mathrm{C}$ allowed the maximum germination rate and percentage, irrespective of the seed source populations. By exposure to 1 and $2 \% \mathrm{NaCl}$ at $17.5^{\circ} \mathrm{C}, 97$ and $93 \%$ of the seeds, respectively, were germinated in $L$. formosanum. The values were comparable to or greater than the highest values obtained from $L$. longiflorum. Both the species could little germinate in $3 \% \mathrm{NaCl}$ treatment. The results indicate that $L$. formosanum is not physiologically distinct from $L$. longiflorum in terms of salinity tolerance. It is concluded that salinity stress, which is one of the major abiotic environmental stresses specific to habitats of $L$. longiflorum, cannot work as a factor of habitat isolation between the two species.
\end{abstract}

\section{INTRODUCTION}

Lilium longiflorum and $L$. formosanum are Asiatic bulbous species very useful as ornamental plant resources. They have been considered to be closely related species as presumed from easy production of horticultural interspecific hybrid, L. x formolongi by artificial hybridization (Okazaki, 1996) and genetic similarity in ITS sequences of rDNA (Dubouzet and Shinoda, 1999). More recently, study on genetic structures of natural populations of the two species has indicated that the $L$. formosanum is highly likely a recent local derivative from $L$. longiflorum (Hiramatsu et al., 2001a).

Both the species are subtropical to temperate insular plants (Wilson, 1925; McRae, 1998). Distribution ranges of the two species are overlapping in the mainland of Taiwan (Shii, 1983). However, habitats where natural populations have been established are remarkably different between $L$. longiflorum and $L$. formosanum, and the species have never been found to be growing sympatrically under natural condition (Hiramatsu et al.,

\footnotetext{
1 Laboratory of Horticultural Science, Agricultural Production, Engineering and Economics Course, School of Agriculture, Kyushu University, Fukuoka 812-8581, Japan

2 Department of Horticulture, National Chiayi University, Chiayi, Taiwan, Republic of China

* Corresponding author (E-mail: m-hirama@agr.kyushu-u.ac.jp)
} 
2001b). L. longiflorum is mainly growing on well-lit grassy fields often dominated with Zoysia sp. or on rocky cliffs, very close to the sea. Such habitats presumably give plants salinity stress. On the other hand, L. formosanum preferably has developed populations in the inland vegetation affected by human and natural disturbance in the margins of arable lands and forests, and on the mountain slopes and cliffs. These habitats are generally considered to be much free from salinity stress.

The environmental factors typical of such species-specific habitats may be closely concerned with adaptive strategies acquired during establishment and/or persistence of the species. We thus hypothesized that salinity stress is one of the major environmental factors differentiating those species' habitats. Salinity is a serious problem encountered by seeds in soils and affects greatly on seedling recruitment (Karssen and Hilhorst, 1992). The major objective in the present study is to estimate effect of salinity stress on germination of $L$. longiflorum and $L$. formosanum.

As for seed germination, temperature is a well-known principle factor. There are, however, few explicit studies of which temperature is the most effective for promoting seed germination of Lilium species. The present study also addressed the effect of temperature on seed germination.

\section{MATERIALS AND METHODS}

Seeds were collected from two populations of $L$. longiflorum located in a coastal area of Kume Shima Island (LKU) in the Ryukyu Archipelago and of Pitouchiao (LPI) in the mainland of Taiwan, and one population of $L$. formosanum located on a mountainous area of Lishan (FLI) in the mainland of Taiwan. They were air-dried at room temperature for maximally nine months until the experiment.

Seven treatments with constant temperature at $5,10,15,17.5,20,25$ and $30^{\circ} \mathrm{C}$ under a dark condition were applied to the seeds using incubators. Three replications of 50 to 60 seeds were subjected to each treatment. Seeds were placed on $50 \mathrm{ml}$ of vermiculite in $9 \mathrm{~cm}$ petri dishes, and then approximately $27 \mathrm{ml}$ of deionized distilled water was added. Agrimycine ${ }^{\circledR}-100$ (18.8\% streptomycin sulfate and $1.5 \%$ oxytetracycline, Pfizer Co.) was added to the germination medium at the concentration of $0.1 \mathrm{gl}^{-1}$ in order to prevent proliferation of bacteria. Germination of each seed was determined by verification of protrusion of the radicle every day.

Sensitivity to salinity during germination was determined at $0,1,2$ and $3 \%$ of sodium chloride $(\mathrm{NaCl})$ solution at $17.5^{\circ} \mathrm{C}$ under a dark condition.

\section{RESULTS AND DISCUSSION}

\section{Germination responses to thermal treatments}

Final germination percentage was nearly $100 \%$ at $10-20^{\circ} \mathrm{C}$, whereas it was significantly decreased as temperature was raised above $20^{\circ} \mathrm{C}$ (Fig. 1). The treatment by the highest temperature of $30^{\circ} \mathrm{C}$ remarkably suppressed the germination percentage as low as $10 \%$ or below. The highest final germination frequency and the earliest germination date when $50 \%$ of final germination percentage was observed were obtained at 17.5 or $20^{\circ} \mathrm{C}$ irrespective of seed source populations. The results indicate that the germination of 


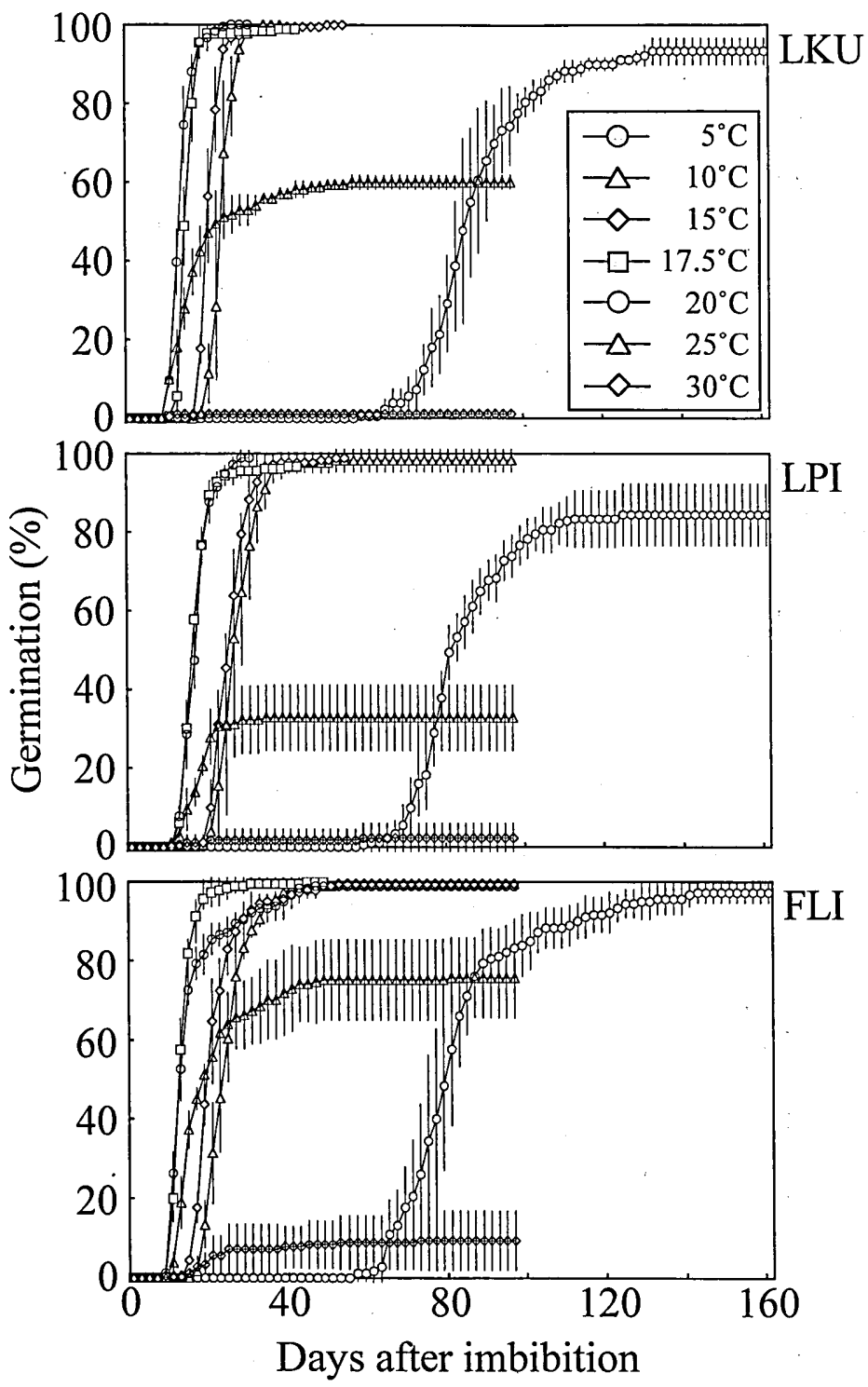

Fig. 1. Germination responses of seeds harvested from two natural populations of Lilium longiflorum and one of $L$. formosanum to seven different levels of constant temperature. Vertical bars of each plot are standard deviations of three replications. LKU, LPI, and FLI, respectively, indicates the seed source population of L. longiflorum from Kume Shima Island in the Ryukyu Archipelago, from Pitouchiao in the mainland of Taiwan, and that of $L$. formosanum from Lishan in the mainland of Taiwan. 


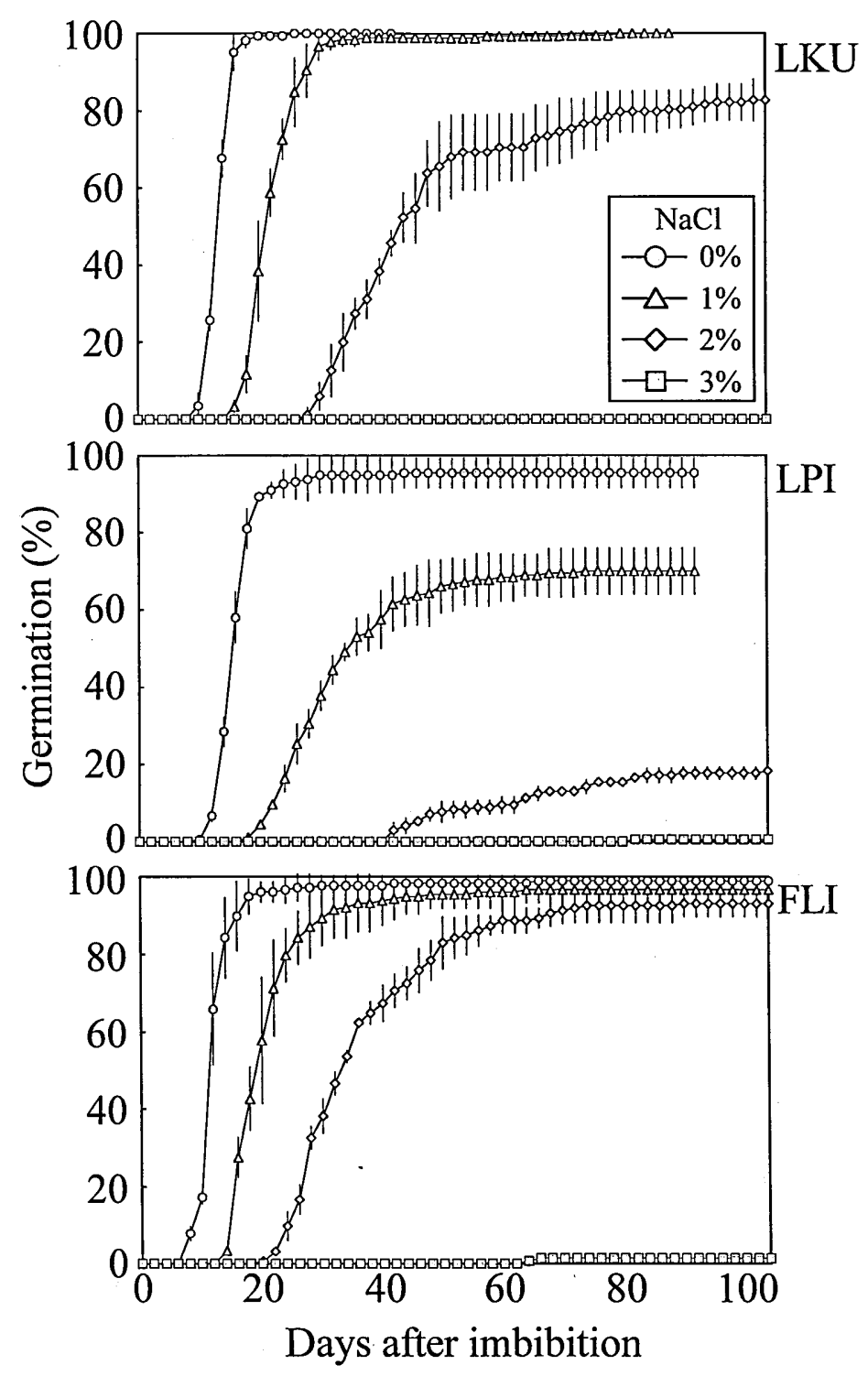

Fig. 2. Germination responses of seeds harvested from two natural populations of Lilium longiflorum and one of $L$. formosanum to four different levels of $\mathrm{NaCl}$ concentration at $17.5^{\circ} \mathrm{C}$. Vertical bars of each plot are standard deviations of three replications. Abbreviations of population names are the same as in Fig. 1. 
L. longiflorum and $L$. formosanum is optimally promoted in the range of $17.5-20^{\circ} \mathrm{C}$, and it is suppressed above $20^{\circ} \mathrm{C}$.

\section{Germination responses to salinity treatments}

Both the final germination percentage and the germination rate decreased with increasing salinity, and little germination was observed in $3 \% \mathrm{NaCl}$ solution for all populations (Fig. 2). Decreasing patterns of the germination rate and final germination percentage with increasing salinity were significantly different among populations studied. For example, the final germination percentage of population LPI was decreased to $18 \%$ in $2 \% \mathrm{NaCl}$ solution, whereas that of population LKU and FLI, respectively was as high as approximately 83 and $93 \%$ in the same salinity treatment. However, even for population LPI, high germination percentage (70\%) was exhibited in $1 \% \mathrm{NaCl}$ solution.

These results indicate that both the species essentially possessed relatively as high tolerance to salinity in their germination as halophytes, in which the delay in germination and final reduction in total number of germinated seeds may not occur until concentrations above $1 \% \mathrm{NaCl}$ (Unger, 1978), and may imply that environmental factors other than the soil salinity stress are responsible for the reason why L. longiflorum and $L$. formosanum do not grow sympatrically. Alternatively, Dubouzet and Shinoda (1999) attributed the reason why $L$. longiflorum is preferably grown on coral limestone to its tolerance to alkaline soil and they also stated that the species grows poorly on acidic soils. Their hypothesis may be significant to be verified.

\section{REFERENCES}

Chii, C. T. 1983 The distribution and variation of Lilium formosanum Wall. and L. longiflorum Thunb. in Taiwan. Liliy Year Book North Amer. Liliy Soc. 36: 48-51

Dubouzet, J. G. and K. Shinoda 1999 Phylogenetic analysis of the internal transcribed spacer region of Japanese Lilium species. Theor. Appl. Genet, 98: 954-960

Hiramatsu, M., K. Ii, H. Okubo, K. L. Huang and C. W. Huang 2001a Biogeography and origin of Lilium longiflorum and $L$. formosanum (Liliaceae) endemic to the Ryukyu Archipelago and Taiwan as determined by allozyme diversity. Amer. J. Bot. 88: 1230-1239

Hiramatsu, M., H. Okubo, K. L. Huang, C. W. Huang and K. Yoshimura 2001b Habitat and reproductive isolation as factors in speciation between Lilium longiflorum Thunb. and L. formosanum Wallace. J. Japan. Soc. Hort. Sci., 70: 722-724

Karsssen, C. M. and H. W. Hilhorst 1983 Effect of chemical environment on seed germination. In "Seeds-the ecology of regeneration in plant communities", ed. by M. Fenner, CAB International, Wallingford, Oxon, UK, pp. 327-348

McRae, E. A. 1998 Lilies-a guide for growers and collectors. Timber Press, Portland, OR., USA, pp. 105-204

Okazaki, K. 1996 Lilium species native to Japan, and breeding and production of Lilium in Japan. Acta Hort., 414: 81-92

Unger, I. A. 1978 Halophyte seed germination. Bot. Rev., 44: 233-264

Wilson, E. H. 1925 The lilies of eastern Asia. Dulau and Company, Ltd., London, UK 